\title{
A sex difference in the recognition level of words'
}

LAU'RENCE A. MESSÉ, PETER R. CHISENA, JR., AND ROBERT H. SHIPLEY ${ }^{2}$, DEPARTMENT OF PSYCHOLOGY, MICHIGAN STATE UNIVERSITY, East Lansing, Mich. 48823

The results from a wide variety of nonverbal visual perception studies have demonstrated that males performed better than females. However, indirect evidence indicated that, for visual perception tasks involving words, females performed better than males. The present study was an attempt to test directly for any sex difference in the recognition level of 23 words. Males were found to have lower mean recognition scores both for the average across the 23 stimuli $(.05<p<.10)$ and for 20 of the 23 words when each was examined separately leight of which were significant at better than the 05 level). In addition, a significant number of males had recognition scores below the median for the total sample $(p<.05)$. These results were discussed in terms of the possibility that this difference was determined by (a) either inherent or experiential variables, and $(b)$ differences either in the ability to organize stimuli or in the tendency to respond to partial cues.

As early as the turn of the century (MacDonald, 1897-1898; Thompson, 1903), and through the ensuing years, systematic studies (e.g., Thurstone, 1944; Sandstrom, 1953; Witkin, Lewis, Hertzman, Meissner, \& Wapner, 1954; Fink, 1959) have demonstrated that males perform a number of visual perception tasks with greater efficacy than do females. However, most, if not all, of these studies involved nonverbal tasks. Moreover, there is some indirect evidence that the superiority of males might not hold for perception tasks involving words: Osgood, Suci, \& Tannenbaum (1957) found that females had shorter latencies when responding to words flashed on a screen for $15 \mathrm{sec}$. This difference in response latency might have been due to a composite of many factors, but it is possible that differential difficulty in perceiving the words had a major influence on the results.

The present study was an attempt to test directly the generalization of male superiority to at least one type of verbal perceptual task: determining the difference in recognition level ${ }^{3}$ for a number of words. If such a phenomenon were true of verbal as well as nonverbal visual perception, then males would have lower recognition levels than would females. On the other hand, if the interpretation of the evidence from Osgood, et al (1957) were valid, then females would have lower recognition levels than males.

Subjects. Fifteen male and 26 female students, enrolled in an introductory psychology course at Michigan State University, and similar to each other in respect to age and year in school, served as the Ss for this study. They all received extra credit for participating in what they were told was a "word-recognition" experiment.

Apparatus and materials. The stimuli used consisted of 23 , four-, five-, and six-letter words randomly selected from the AA frequency category (occurring at least 100 times per million words) of the Thorndike and Lorge (1944) word count. These words were printed in bold-face capitals and mounted as slides. A double-track tachistoscope was used to present the words: one track was used to present the actual words, while the other projected a "word frame" which eliminated flashes of light and gave the Ss a more structured area to focus upon.

Procedure. The Ss were run in four, mixed-sex groups of between eight and 12 persons each. All words were presented once at each of 12 exposure times (in fractions of a second): $.01 ; .02 ; .03 ; .04 ; .05 ; .06 ; .07 ; .08 ; .09 ; .10$; $.50 ; 1.00$. The time between an exposure of a given word was about $5 \mathrm{sec}$, and between successive words, about $10 \mathrm{sec}$. The words were projected upon the smooth, white wall of the experimental room; the Ss were seated at tables which were placed 10-15 ft from the viewing surface. After viewing each exposure, the Ss wrote down whatever they had perceived in the word frame-individual letters, groups of letters, or a whole word. If a $S$ perceived nothing at all on a given exposure, he or she drew a line through the appropriate space on the answer sheet. All Ss responded to the 23 stimuli in this manner.
Results and Discussion. The recognition score for a given $S$ on a given word was defined as that exposure time when the $S$ first responded correctly to the stimulus. The mean recognition score across the 23 words was tabulated for each $S$ and classified by sex. Further, since there was concern over the comparability of conditions across experimental sessions, the scores were also classified according to the session in which the data for each $S$ were obtained.

This overall classification indicated that males more easily recognized the words (i.e., had lower mean recognition scores) than did females, and that there were no systematic differences in recognition level between the four sessions. An analysis of variance tended to support these conclusions: (a) the lower mean recognition score for males was significant at about the .08 level $(F=$ 3.22 , $\mathrm{df}=1 / 33$ ); (b) there were no systematic variations across sessions, both in terms of absolute differences $(F<1.00)$ and, more importantly, in terms of differences between males and females $(F<.08)$.

To make sure that the mean recognition scores were a valid reflection of a general tendency and not distorted by extreme differences in a small proportion of stimuli, the data were examined separately for each word. It was found that males had a lower score than did females for 20 of the 23 words. Over one-third of these differences, when subjected to $t$ tests, were significant at better than the $.05 \mathrm{level}$, and over $56 \%$ were significant at better than the .10 level. Table 1 presents a frequency distribution of the 23 stimuli classified by the significance levels of these sex differences.

Further, to make sure that this sex difference was not due to the extreme but consistent behavior of a very few males and/or females, the mean recognition score for each person was examined in terms of the median of such scores for the total sample. It was noted that just $20 \%$ of the male Ss had mean recognition scores above the median, while less than $35 \%$ of the female Ss had scores below the median. This difference in the distribution of scores by sex was significant at better than the .05 level $\left(\mathrm{X}^{2}=5.02\right.$, two-tailed median test)

These findings, coupled with the results of prior research on visual perception, support the existence of a general sex difference in favor of males. These results give rise to two major questions: (a) Are such findings due to inherent differences in the neural/ hormonal mechanisms mediating visual perception in males and females, or to modifications of their sensory-cognitive systems caused by different social experiences? (b) Are such findings due to the differential ability of males and females to organize visual stimuli into meaningful patterns (i.e., differences in the reception side of perception), or to differential tendencies to respond under varying conditions of uncertainty (i.e., differences in the response side of perception)?

Unfortunately, data which would provide a definitive answer to either question are not available at present. However, there is some indirect evidence which does support the position that males are

Table 1

The Distribution of Sex Differences per Word Classified by $p$ Value

p Value

Frequency

Male Ss $>$ Female Ss: $p>.25$

Male $\mathrm{Ss}<$ Female Ss: $\mathrm{p}>.20$

$<.20$

$<.10$

$<.05$

$<.025$

$<.01$

Total

23 
more willing to take a chance and guess when operating under conditions of uncertainty than are females. The senior author has unpublished data which reveal that females avoid taking risks to a greater extent than do males (as measured by the risk-avoidance subscale of the personality/attitude inventory developed by Shure \& Meeker, 1965). This being the case, it follows that females would be more cautious when responding in situations where only partial cues were present.

However, it is obvious that studies which address themselves to these questions in a more direct manner remain to be done. Advances in biopsychology and cross-cultural methods should provide evidence which evaluates the validity of postulating inherent differences. Research designs, similar to that used by Bootzin \& Natsoulas (1965) in their demonstration of the existence of perceptual defence, should provide adequate controls to test directly the proposition that such differences are due to differential response tendencies. In sum, at the moment we can only say with some degree of certainty that a sex difference does exist; as yet, we cannot say why.

\section{REFERENCES}

BOOTZIN, R. R., \& NATSOULAS, T. Evidence of perceptual defense uncontaminated by response bias, J. Pers. Soc. Psychol., 1965, 1, 461468.

FINK, D. M. Sex differences in perceptual tasks in relation to selected personality variables. Unpublished doctoral dissertation, Rutgers University, 1959

MacDONALD, A. Experimental study of children, including anthropometrical and psycho-physical measurements of Washington school children, and a bibliography, Report of the Commission of Education, Washington, 1897-1898.

OSGOOD, C. E., SUCI, G. J., \& TANNENBAUM, P. H. The measurement of meaning. Urbana: University of Illinois Press, 1957.

SANDSTROM, C. I. Sex differences in localization and orientation. Acto Psychologica, 1953, 9, 82-96.

SHURE, G. H., \& MEEKER, R. J. A personality/attitude schedule for use in experimental bargaining studies, Tech Memorandum No. TM - 2543, Systems Development Corporation, 1965.

THOMPSON, HELEN B. The mental traits of sex. Chicago: Univ. of Chicago Press, 1903.

THORNDIKE, E. L., \& LORGE, I. The teacher's word book of 30,000 words. New York: Bureau of Publications, Teachers College, 1944.

THURSTONE, L. L. A factorial study of perception. Chicago: Univ. of Chicago Press, 1944.

WITKIN, H. A., LEWIS, H. B., HERTZMAN, M., MEISSNER, P. B., \& WAPNER, S. Personality through perception, an experimental and clinical study. New York: Harper Bros., 1954.

\section{NOTES}

1. The authors wish to express their appreciation to Paul Bakan for his very insightful comments on an earlier draft of this paper. We also wish to thank Burton Alperson for his help in procuring the use of a tachistoscope and Charles Hanley for his help in recruiting subjects.

2. Now at the University of Iowa.

3. The present research used the first recognition trial in an ascending series of the method of limits as the index of recognition level. 